107 Royal Netherlands Institute for Sea Research

This is a postprint of:

Ponsoni, L., Aguiar-Gonzáles, B., Maas, L.R.M., Aken, H.M. van \& Ridderinkhof, H. (2015). Long-term observations of the East Madagascar Undercurrent. Deep-Sea Research, Part I. Oceanographic Research Pap, 100, 64-78

Published version: $\underline{\mathrm{dx} . \text { doi.org/10.1016/j.dsr.2015.02.004 }}$

Link NIOZ Repository: $\underline{w w w . v l i z . b e / n l / i m i s ? m o d u l e=r e f \& r e f i d=247524 ~}$

[Article begins on next page]

The NIOZ Repository gives free access to the digital collection of the work of the Royal Netherlands Institute for Sea Research. This archive is managed according to the principles of the Open Access Movement, and the Open Archive Initiative. Each publication should be cited to its original source - please use the reference as presented.

When using parts of, or whole publications in your own work, permission from the author(s) or copyright holder(s) is always needed. 


\title{
Long-term observations of the East Madagascar Undercurrent
}

\author{
L. Ponsoni ${ }^{\mathrm{a}, *}$, B. Aguiar-González ${ }^{\mathrm{a}, *}$, L. R. M. Maas ${ }^{\mathrm{a}, \mathrm{b}}$, H. M. van Aken ${ }^{\mathrm{a}}$, H. \\ Ridderinkhof ${ }^{a, b}$ \\ ${ }^{a}$ NIOZ Royal Netherlands Institute for Sea Research, P.O. Box 59, 1790 AB Den Burg, \\ Texel, The Netherlands \\ ${ }^{b}$ Institute for Marine and Atmospheric Research, Utrecht University, Princetonplein 5, \\ 3584 CC Utrecht, The Netherlands
}

\section{Abstract}

1 An array of five moorings was deployed at $23^{\circ} \mathrm{S}$ off eastern Madagascar and

${ }^{*}$ Corresponding first author. Tel.: +31 (0)222 369310

Email addresses: lponsoni@nioz.nl (L. Ponsoni), Borja.Aguiar.Gonzalez@nioz.nl (B. Aguiar-González), Leo.Maas@nioz.nl (L. R. M. Maas), hm.vanaken@texel.nl (H. M. van Aken), Herman.Ridderinkhof@nioz.nl (H. Ridderinkhof) 
13

23

inhibited by a stronger poleward barotropic contribution. The wavelet spectrum analysis of the transport time series displays two dominant frequency bands: (i) nearly bi-monthly (46-79 days), previously observed in the surface EMC, and attributed to the forcing of barotropic waves generated in the Mascarene Basin; and, (ii) nearly semi-annual (132-187 days), which seems related to the semi-annual cycle in the equatorial winds near the Indian Ocean eastern boundary. A historical dataset of temperature salinity Argo profiles was used to investigate the spatial variability of the thermohaline properties at intermediate levels. Lastly, Argo-derived velocities suggest an undercurrent flowing upstream until approximately $17^{\circ} \mathrm{S}$.

Keywords: East Madagascar Undercurrent, East Madagascar Current, Indian Ocean, Western Boundary Current, Bi-monthly variability, Semi-annual variability 


\section{Introduction}

An equatorward undercurrent flowing opposite and beneath a surface current is a recurring oceanographic feature in western boundary current systems. Such a feature has been universally observed at ocean western boundaries. For instance, the Luzon Undercurrent in the North Pacific (Hu and Cui, 1991; Hu et al., 2013); the East Australian Undercurrent in the South Pacific (Godfrey et al., 1980; Schiller et al., 2008); the Intermediate Western Boundary Current in the South Atlantic (Evans and Signorini, 1985; da Silveira et al., 2004); and, in the South Indian Ocean, the Agulhas Undercurrent (Beal and Bryden, 1997), the Mozambique Undercurrent (de Ruijter et al., 2002; van Aken et al., 2004) and the East Madagascar Undercurrent (Nauw et al., 2008), which the study of its vertical structure, transport and variability composes the main scope of this paper.

Historically, the interface between the undercurrents and the polewarddirected surface currents has been largely employed as a reference level (e.g., Swallow and Worthington, 1961) for estimating absolute geostrophic velocities via thermohaline properties and the dynamic method, especially when and where direct velocity measurements are scarce (Fomin, 1964). Also, undercurrents might play a role in the heat and salt budget (Bryden and Beal, 2001) and, consequently, be related with the world's climate. Bryden and Beal (2001) showed that the Agulhas Undercurrent reduces the Agulhas Current transport by about $15 \mathrm{~Sv}$, attenuating its poleward heat transport.

In terms of global climate, the South-West Indian Ocean (SWIO) has a crucial contribution to the meridional overturning circulation, since in this region an interocean exchange occurs where large amounts of relatively warm 
and salty water leak from the Indian to the Atlantic Ocean through the Agulhas Current (Olson and Evans, 1986; Gordon et al., 1992; de Ruijter et al., 1999; Lutjeharms, 2006; Beal et al., 2011).

In turn, the surface poleward-directed Agulhas Current is fed upstream by the flows from the Mozambique Channel and the East Madagascar Current. Such a connection does not seem straightforward between the equatorwarddirected undercurrents. Supported by numerical simulations, Biastoch et al. (2009) stated that there is no direct connection between the Agulhas Undercurrent and the undercurrents in the Mozambique Channel and east of Madagascar.

Nauw et al. (2008) described an East Madagascar Undercurrent (EMUC) 50-90 km wide flowing below and opposite to the poleward East Madagascar Current (EMC), with its core hugging the continental slope at depths of about $1300 \mathrm{~m}$. Its description is based on in situ measurements of velocity and water mass analysis (hydrographic, nutrients and oxygen data) carried out at four quasi-synoptic vertical cross-shore transects around the south of Madagascar. Velocities of the undercurrent core reached over $20 \mathrm{~cm} \mathrm{~s}^{-1}$, yielding an equatorward volume transport of $2.8( \pm 1.4) \mathrm{Sv}$. Water mass analysis suggested that the EMUC core was mostly composed of diluted Red Sea Water (RSW) from the Mozambique Channel.

Nevertheless, since Nauw et al's (2008) work is based only on a few snapshots, issues related to the EMUC persistence, temporal variability of its velocity and volume transport, variations in its vertical structure, its mean flow, thermohaline characteristics of surrounding waters, amongst others, still need to be addressed. The present study provides further insight on 
those issues based on 2.5 years of continuous velocity measurements.

The paper is organized as follows: the dataset description and basic treatment are covered in Section 2; the mean flow, volume transport and dominant bands of variability are addressed in Section 3; considerations on the EMUC baroclinic/barotropic partitioning are presented in Section 4; the upstream extension of the EMUC and the spiciness of intermediate waters around Madagascar Island are investigated in Section 5; and, finally, Section 6 presents a discussion and draws some conclusions about the principal results.

\section{Data and data processing}

As a basis for this study we use a five-mooring array of velocity observations. The mooring line was deployed on the southeastern coast off Madagascar, nominally at $23^{\circ} \mathrm{S}$, across the continental slope and perpendicular to the shoreline (and isobaths), as a part of the "INdian-ATlantic EXchange in present and past climate" (INATEX) project (Fig. 1). Offshore distances from the coast for each deployment are, respectively, 6.3 (EMC1), 28.6 (EMC2), 54.8 (EMC3), 68.7 (EMC4) and $120.8 \mathrm{~km}$ (EMC5).

All the moorings were equipped with upward-looking Acoustic Doppler Current Profilers (ADCP - RDI Workhorse Long Ranger $75 \mathrm{kHz}$ with profiling range of about $500 \mathrm{~m}$ ) and Recording Current Meters (RCM - Aanderaa RCM 11) placed in-line along the mooring cables (Fig. 2a). RCM and ADCP sample rates were set to 20 and 30 minutes, respectively. From here on, every individual instrument will be called $\operatorname{EMC} X-Y$, where $X$ represents the mooring number and $Y$ the nominal depth (example: EMC2-1600 for the 
instrument in the mooring EMC2 at nominally $1600 \mathrm{~m}$ depth).
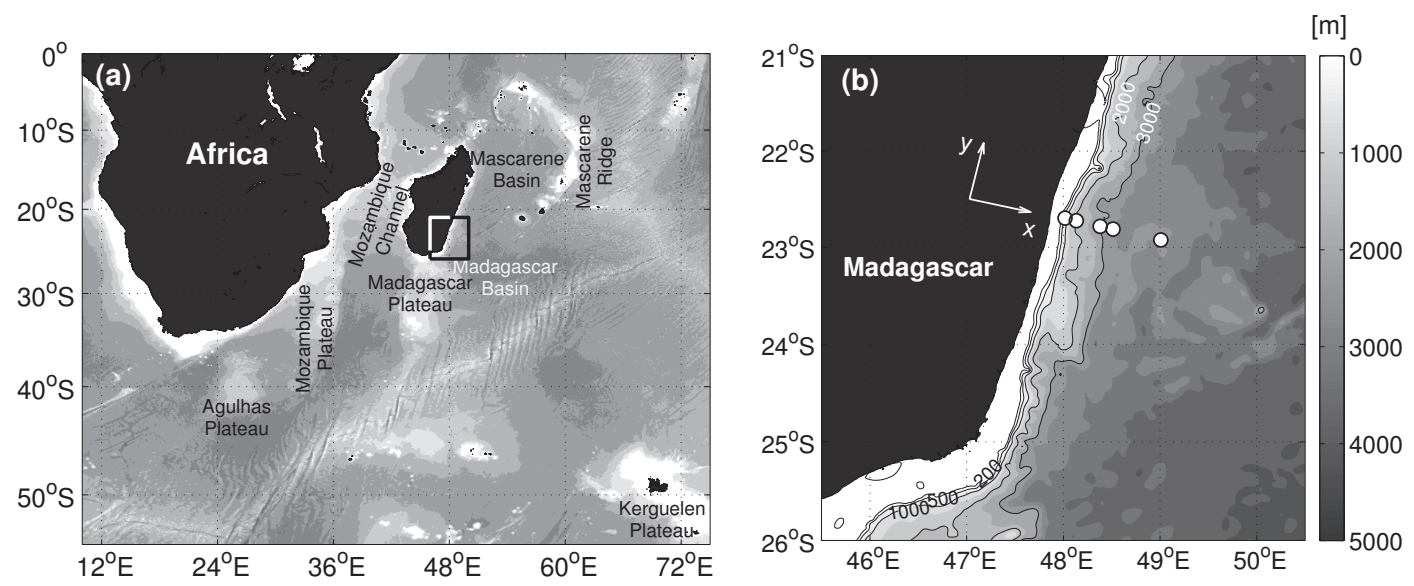

Figure 1: (a) Bathymetric map of the South-West Indian Ocean (SWIO). (b) Zoom of the area of study indicated by the square drawn in (a). White circles represent the locations of the INATEX moorings. Isobaths of 200, 500, 1000, 2000 and $3000 \mathrm{~m}$ are plotted in the map.

The INATEX deployment cruise (ALGOA179, named after the oceanographic vessel) took place in October 2010, while the recovery cruise (ALGOA197) was carried out on April 2013. All the ADCPs sampled continuously from deployment until recovery, except the upper ADCP at EMC3 which failed for the whole period due to leakage and internal damage caused by acid from the batteries. RCM devices remained operational until the middle of March 2013, except EMC3-1500 and EMC4-2000, which worked properly until the end of September 2012, from whereon we considered the line mooring composition without those two instruments. After the first basic data treatment removed bad quality data and addressed blow-down correc- 
tions, the time series were synchronized and truncated from 7 Oct 2010 to 12 Mar 2013 (91\% of daily data return), accumulating approximately 2.5 years of continuous data.

All current velocity records went through low pass filtering (forwardbackward Butterworth filter), with a 3.5 day cut-off period, in order to remove tidal and near-inertial motions from the time series (Ridderinkhof et al., 2010; Ullgren et al., 2012), since this study is focused on the mesoscale geostrophic circulation. The data were subsampled daily at noon. Meridional and zonal velocities were rotated clockwise $12.9^{\circ}$ from north, so that the flow components are oriented parallel/perpendicular to the coast. These velocity components are referred to as alongshore $(v)$ and cross-shore $(u)$ components.

Following Ridderinkhof et al. (2010), cross-correlations among the instruments were determined to support spatial interpolations. These authors found stronger correlations between velocity time series from the same mooring, mainly over vertical separations of $500 \mathrm{~m}$. The INATEX data also present strong correlations between time series from vertically adjacent instruments, although some good horizontal correlations are also observed (Fig. 2b). Horizontal correlations are drastically affected if time series from any mooring are combined with EMC5, since this mooring was deployed near the offshore front of the EMC system. But still, even in EMC5 the vertical correlations are strong (not shown).

Time synchronized data from ADCPs and RCMs were linearly merged, first vertically onto $8 \mathrm{~m}$ bins (ADCP vertical resolution) at standard depth levels, and subsequently horizontally, by linear interpolation applied for each 


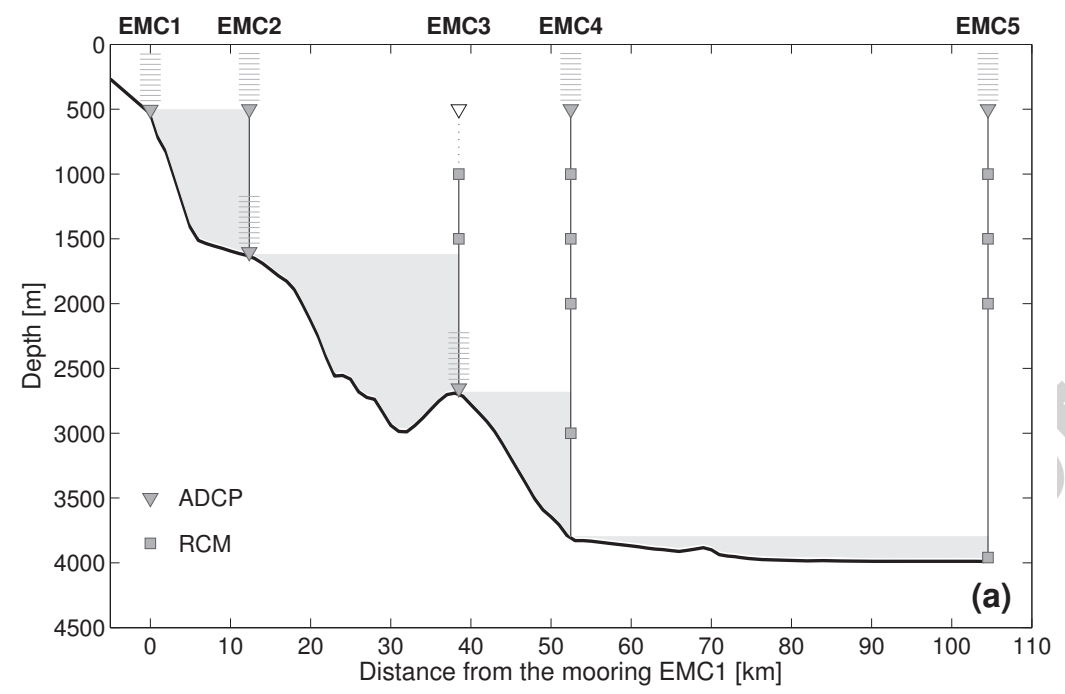

\begin{tabular}{|c|c|c|c|c|c|c|c|c|c|c|c|c|}
\hline EMC1-0500- & 1.00 & & & & & & & & & & & (b) \\
\hline EMC2-0500- & 0.16 & 1.00 & & & & & & & & & & \\
\hline EMC2-1260- & 0.14 & 0.50 & 1.00 & & & & & & & & & \\
\hline EMC2-1500- & -0.07 & 0.03 & 0.15 & 1.00 & & & & & & & & \\
\hline EMC3-1000- & 0.11 & 0.77 & 0.78 & 0.07 & 1.00 & & & & & & & \\
\hline EMC3-1500- & 0.14 & 0.54 & 0.66 & 0.05 & 0.73 & 1.00 & & & & & & \\
\hline EMC3-2500- & 0.04 & 0.22 & 0.24 & -0.02 & 0.34 & 0.42 & 1.00 & & & & & \\
\hline EMC4-0500- & -0.05 & 0.76 & 0.33 & 0.05 & 0.64 & 0.38 & 0.10 & 1.00 & & & & \\
\hline EMC4-1000- & 0.00 & 0.75 & 0.50 & 0.08 & 0.85 & 0.56 & 0.20 & 0.82 & 1.00 & & & \\
\hline EMC4-1500- & 0.02 & 0.55 & 0.43 & 0.08 & 0.74 & 0.56 & 0.41 & 0.58 & 0.81 & 1.00 & & \\
\hline EMC4-2000- & 0.05 & 0.33 & 0.32 & 0.02 & 0.54 & 0.46 & 0.62 & 0.33 & 0.51 & 0.78 & 1.00 & \\
\hline EMC4-3000- & 0.06 & 0.12 & 0.08 & -0.09 & 0.21 & 0.20 & 0.52 & 0.10 & 0.17 & 0.40 & 0.66 & 1.00 \\
\hline
\end{tabular}

Figure 2: (a) Vertical sketch of the INATEX moorings where RCMs are represented by squares and ADCPs by triangles and small horizontal lines, which indicate the upwardlooking range of the ADCP. The empty triangle in EMC3 shows the faulty instrument. The gray shaded areas show the regions where extrapolation is applied. (b) Correlation coefficients calculated in between different pairs of time series (instruments). Values in bold are significant ( $\mathrm{p}$-value test, testing the hypothesis of no correlation) for a $95 \%$ confidence interval. 
standardized depth level onto a horizontal grid of $1 \mathrm{~km}$. Therefore, the cross-shore grid resolution utilized for further transport calculations is $1 \mathrm{~km}$ (distance) $\times 8 \mathrm{~m}($ depth $)$.

Before computing volume transport estimates, an essential step concerns the choice of the extrapolation method used to fill in empty data regions. These empty areas are created between every pair of neighboring moorings and the bathymetry below the shallowest station of this pair (gray shaded areas in Fig. 2a). This choice presents an infamous problem, especially pressing in regions near a steep continental slope.

Observations from the near-bottom ADCP at EMC2 suggest speed attenuation towards the seafloor. Since the first measurement from this instrument took place at $\sim 20 \mathrm{~m}$ from the bottom, it is difficult to infer whether or not the current speed decreases to zero right above the seafloor. On the other hand, some studies have shown that under certain conditions an undercurrent core near the bottom can create a slippery boundary layer for itself (MacCready and Rhines, 1993) and eventually reduce (or eliminate) bottom friction effects (Chapman and Lentz, 1997).

For the sake of completeness, we apply the two extreme boundary conditions (no-slip and full-slip) following previous works (Beal and Bryden, 1997; Nauw et al., 2008), as well as a third alternative method based on optimal interpolation (Carter and Robinson, 1987; da Silveira et al., 2004). In this way a global overview of the EMUC transport is attempted, from underestimated (no-slip condition) to overestimated (full-slip condition) values.

The optimal interpolation has been performed as introduced by Carter and Robinson (1987) for oceanographic data gridding purposes, where a clas- 
sical Gaussian correlation function $C(x, z)$ is used as follows:

$$
C(x, z)=(1-\epsilon) e^{\left(-\frac{x^{2}}{L_{x}^{2}}-\frac{z^{2}}{L_{z}^{2}}\right)},
$$

where $x$ and $z$ are horizontal and vertical grid points, respectively, $\epsilon=0.1$ is the random sampling error variance, and $L_{x}=50 \mathrm{~km}$ and $L_{z}=500 \mathrm{~m}$ represent the horizontal and vertical correlation lengths. $L_{x}$ and $\epsilon$ were estimated from the fit by non-linear regression to the theoretical one-dimensional (horizontal) form of the Eq. 1. This method consists in the best fitting of the Gaussian shape to the horizontal correlation pairs from all velocity series around the EMUC depths. $L_{z}$ was chosen as a typical scale for the EMUC resulting from the strongly sheared velocity profiles observed at EMC2 (assumed as the core's location of the EMUC, see Section 3). A reduced number of well equidistantly time series in EMC2 prohibited the estimation of $L_{z}$ in the same way as $L_{x}$ was estimated.

Absolute dynamic topography $(\eta)$ sampled from satellite is used to compare the cross-shore gradients of this property with the EMUC velocities. To achieve this, we linearly interpolate a time series of $\eta$ collocated onto the positions of the moorings. The original data for this analysis contains daily $\eta$, which is the sum of sea level anomaly and mean dynamic topography. The altimeter products were produced by Ssalto/Duacs and distributed by Aviso (http://www.aviso.altimetry.fr/duacs/), with support from Cnes (Rio et al., 2011). Here we use the "all sat merged" series of the delayed-time altimeter product, which is provided with a spatial resolution of $0.25^{\circ}$.

Water mass properties carried by the undercurrent were investigated using a subset of potential temperature $(\theta)$ and salinity $(S)$ profiles from the 
global array of free-drifting Argo floats. The Argo database consists of a collection of profiling floats which monitor the upper 2000 dbar of the ocean at regular 10-day intervals. All Argo profiles shown in this study were downloaded on July 2014 from the Global Argo Data Repository of the National Oceanographic Data Center (NODC). To ensure robustness of the results, only profiles in delayed mode after passing the quality control were used. Additionally, all profiles were visually inspected with their neighbouring counterparts. Floats with suspicious profiles either in temperature or salinity, or in the Argo gray list, were discarded. Also, profiles shallower than $1000 \mathrm{~m}$ depth were discarded as they are not deep enough to capture the intermediate waters at which the undercurrent is flowing. As a result, a total of 1776 profiles distributed from Sep/2001 to Dec/2013 are used. The span of 12 years of data and wide spatial coverage provides support that our analysis describes long-term $\theta$-S patterns.

Finally, we use the ANDRO (Ollitrault and Rannou, 2013) current velocities deduced at surface and near $1000 \mathrm{~m}$ depth ("parking" depth) from Argo float displacements to assist discussion on the location of Argo floats sampling the undercurrent.

\section{The East Madagascar Undercurrent}

\subsection{Observed velocities and mean flow}

Considering the geostrophic nature of the EMC system, one might expect an undercurrent strongly aligned to the shoreline and isobaths given its tendency to conserve potential vorticity. Fig. 3a shows the standard deviation ellipses and the mean vectors of the velocity component decomposed along 
the principal axis. Notice that the mean flow along the major axis is stronger at EMC2, which is rotated $13^{\circ}$ from north. This angle is consistent with the alongshore rotation described in the previous section (12.9 from north).

Fig. 3b shows the alongshore velocity gridded in the vertical transect and averaged over the whole time span. An undercurrent core near EMC2 at depths around $1260 \mathrm{~m}$ is suggested by the figure. A poleward integrated transport of $-18.4 \mathrm{~Sv}$ is computed from this mean velocity field. When calculated only in the area enclosed by the $0 \mathrm{~cm} \mathrm{~s}^{-1}$ isotach (green line), the mean velocity field generates an equatorward transport of $0.24 \mathrm{~Sv}$.

In this section, the description of the velocity time series in the EMUC domain is focused on measurements recorded by EMC2-1600, EMC3-1500 and EMC3-2600. Also, an interpolated position in between the last two (referred to as EMC2-2000) is explored, so we have a point near the uppermost measurements from the ADCP profiler EMC3-2600 and, at the same time, we can inspect the performed vertical gridding. Table 1 summarizes some velocity statistics, such as mean, maximum and variance of both alongshore and cross-shore velocity components. Despite the focus on those time series, the other neighboring instruments will be important to account for the EMUC transport in cases of a spread-out undercurrent or, for instance, in the case of EMC2-0500, to define the sheared interface EMC-EMUC.

Fig. 4 shows the time series of alongshore velocity at the selected positions. Equatorward currents sampled by EMC2-1600 were generally stronger than those observed at other instruments. The global maximum velocity was observed to be $27.3 \mathrm{~cm} \mathrm{~s}^{-1}$, on 21 Jan 2012 at $1100 \mathrm{~m}$ (black star in Fig. 4a). Fig. 4b presents the velocity time series extracted from EMC2-1600 

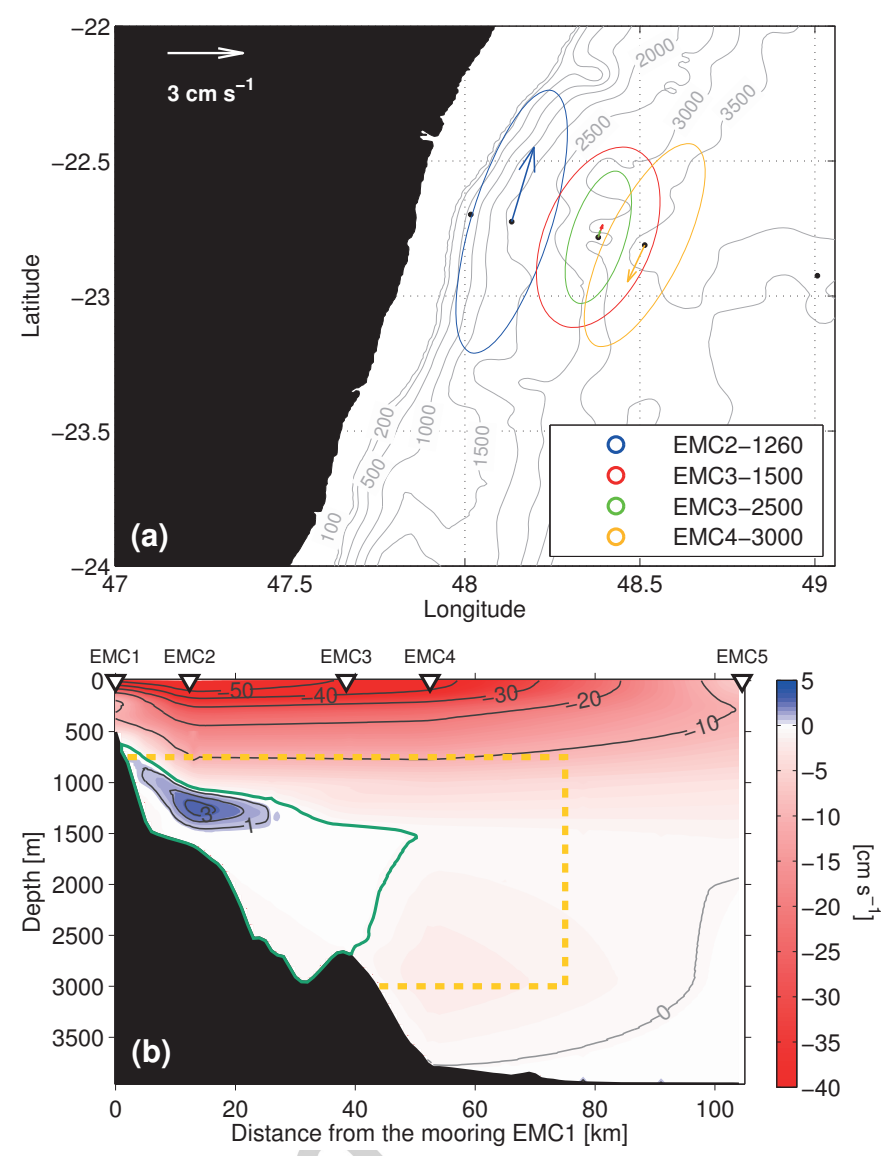

Figure 3: (a) Standard deviation ellipses and mean vectors of the velocity component decomposed along the principal axis from the EMC2-1260, EMC3-1500, EMC3-2500 and EMC4-3000 time series. The main axis for each time series (rotated clockwise 13, 15.1, 12.6 and $19.9^{\circ}$ from north, respectively) is defined as the angle in which the sum of the squares of the zonal and meridional velocities relative to the mean flow are maximal. (b) Alongshore mean flow of the EMC system averaged over the whole time series. Optimal interpolation is applied as extrapolation method. EMUC (EMC) mean flow is shown in shades of blue (red). Dashed yellow rectangle encloses the area where the Equatorward Volume Transport (EVT) is calculated (see Section 3.2). The green contour represents the $0 \mathrm{~cm} \mathrm{~s}^{-1}$ isotach, and it encloses the area where the Net Volume Transport (NVT) is calculated (see Section 3.3). 
Table 1: Properties of the EMUC sampled at the instruments EMC2-1600, EMC3-1500, EMC3-2600, as well as at the interpolated position (EMC3-2000). Alongshore and crossshore velocity components are represented by $v$ and $u$, respectively. The alongshore axis is rotated $12.9^{\circ}$ degrees from north. The statistics are based on a total of 888 days.

\begin{tabular}{|c|c|c|c|c|}
\hline Instrument & EMC2-1600 & EMC3-1500 & EMC3-2000 & EMC3-2600 \\
\hline Depth (m) & $1260^{a}$ & 1500 & 2000 & $2500^{b}$ \\
\hline Height above bottom (m) & 304 & 1150 & 650 & 150 \\
\hline$v$, mean velocity $\left(\mathrm{cm} \mathrm{s}^{-1}\right)$ & 4.1 & 0.7 & 0.6 & 0.4 \\
\hline$v$, velocity variance $\left(\mathrm{cm}^{2} \mathrm{~s}^{-2}\right)$ & 39.9 & 19.0 & 23.4 & 10.0 \\
\hline$v$, max velocity $\left(\mathrm{cm} \mathrm{s}^{-1}\right)$ & 23.8 & 12.1 & 153 & 9.3 \\
\hline$\#$ days of $v>0$ flow ${ }^{c}$ & 692 & 521 & 504 & 479 \\
\hline$v>0$, mean velocity $\left(\mathrm{cm} \mathrm{s}^{-1}\right)^{d}$ & 6.4 & 8. & 4.1 & 2.76 \\
\hline$u$, mean velocity $\left(\mathrm{cm} \mathrm{s}^{-1}\right)$ & -0.4 & & 0.1 & -0.1 \\
\hline$u$, velocity variance $\left(\mathrm{cm}^{2} \mathrm{~s}^{-2}\right)$ & 2.4 & 4.4 & 4.2 & 1.1 \\
\hline$u$, max velocity $\left(\mathrm{cm} \mathrm{s}^{-1}\right)$ & 7.5 & 8.7 & 7.0 & 4.5 \\
\hline
\end{tabular}

${ }^{a}$ Extracted from EMC2-1600 ADCP, representing the maximum mean velocity level.

${ }^{b}$ Arbitrary level from the EMC3-2600 ADCP.

${ }^{c} v>0$ represents equatorward flow.

${ }^{d} v$ must be positive, so they do not necessarily have Gaussian statistics.

at $1260 \mathrm{~m}$. Strong velocities over $20 \mathrm{~cm} \mathrm{~s}^{-1}$ were found only on a few occasions ( $1 \%$ of the whole time span, 9 days), with a peak velocity of $23.8 \mathrm{~cm}$ $\mathrm{s}^{-1} \cdot 13.5 \%$ (121 days) of this same time series were dominated by velocities between 10 to $20 \mathrm{~cm} \mathrm{~s}^{-1}$, and $63.5 \%$ (562 days) between 0 to $10 \mathrm{~cm} \mathrm{~s}^{-1}$. The remaining 22\% (196 days) were marked by a reversal to poleward flow. For the other three positions (EMC3-1500, EMC3-2000 and EMC3-2600) velocities are typically weaker than $10 \mathrm{~cm} \mathrm{~s}^{-1}$ (Figs. 4c-f). 

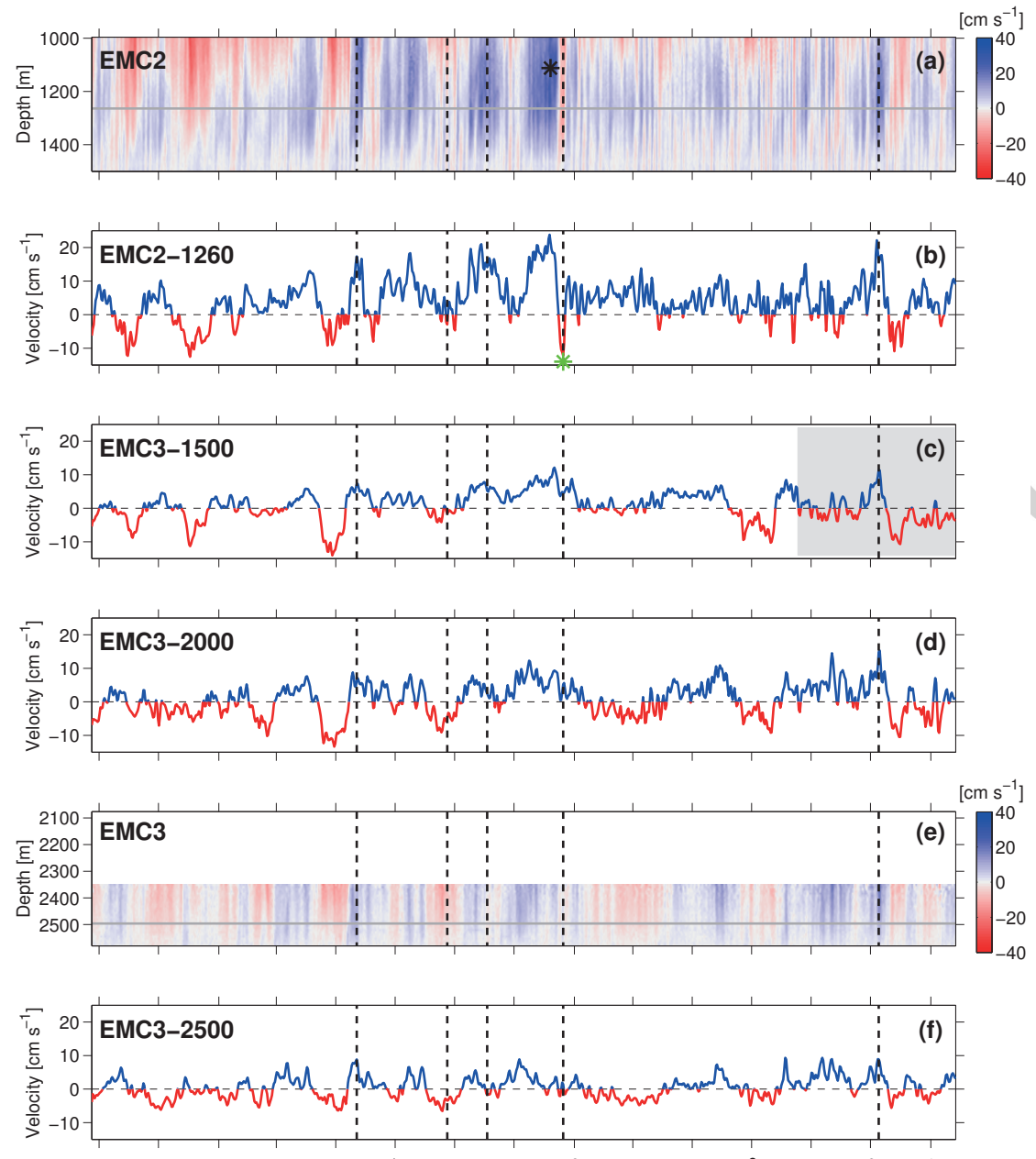

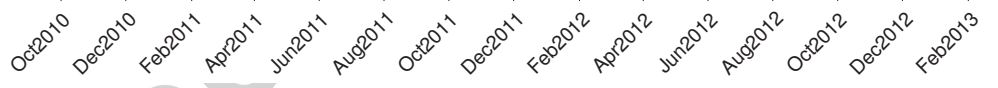

Figure 4: Alongshore $(v)$ velocity time series from the instruments placed into the undercurrent mean domain. (a) and (e) represent the time series over the depth range sampled by the EMC2-1600 and EMC3-2600 ADCPs. (b), (c), (d) and (f) show the time series at single individual levels. Blue (red) colors represent equatorward (poleward) flow. Vertical black dashed lines indicate the moments when the vertical transects are shown in Fig. 5. Horizontal gray lines in (a) and (e) represent the level plotted in (b) and (f), respectively. The black star in (a) highlights the time and level with the velocity peak. Green star in (b) shows a strong flow reversal only at EMC2-1600. The gray shadow at the end of (c) shows the time span when velocity has been reconstructed (see Section 2). Ticks on the $\mathrm{x}$-axis are placed at noon on the 15 th day of the respective month. 
The EMUC core may not be at the location of EMC2, but taking into account the sharp horizontal decay of the undercurrent velocities between that mooring position and EMC3, as well as the relatively small distance between EMC2 and the continental slope (at the undercurrent depths), it is fair to consider that location as the core position of the EMUC, as previously suggested by the mean flow in Fig. 3b. In this sense, an average core at intermediate depths is estimated from the data sampled by EMC2-1600. The mean core is placed at around $1260 \mathrm{~m}$ depth, approximately $400 \mathrm{~m}$ from the seabed, and it exhibits an average (and standard deviation) velocity of $4.1( \pm 6.3) \mathrm{cm} \mathrm{s}^{-1}$. If the average is taken only over the equatorward flow (positive values in Fig. 4b) this mean speed increases to $6.4( \pm 4.8) \mathrm{cm} \mathrm{s}^{-1}$.

Note that velocities in EMC3-2000 (Fig. 4d) present variance and equatorward mean flow higher than the two adjacent EMC3-1500 and EMC3-2500 (Table 1). This fact occurs due to the shape of the undercurrent hugging the continental slope, so that EMC3-2000 is closer to the undercurrent core than EMC3-1500 and EMC3-2500.

Remarkably, only on a single occasion there was a strong reversal in the flow at EMC2 $=1600$ that was not followed by the other instruments (green star in Fig. 4b). During this event, occurring at the beginning of February 2012, the undercurrent core seems to have shifted offshore, suggesting the presence of a secondary deeper core, as can be inferred due to the persistence of the equatorward flow recorded in the other instruments at the same moment (Figs. 4c-f). Besides the primary core in the vicinity of EMC2, at different moments the EMUC flow seems to contain a concomitant secondary deeper core below 2000 m. de Ruijter et al. (2002) and Beal (2009) also ob- 
served a secondary core in the Mozambique Undercurrent and in the Agulhas Undercurrent, respectively.

Fig. 5 shows five snapshots representing different EMUC velocity scenarios encountered. First, the undercurrent flow reinforced by a cyclonic eddy (06 Jul 2011; Fig. 5a). Second, the absence of any equatorward flow (07 Oct 2011; Fig. 5b). Third, an undercurrent flowing only with the primary intermediate core (17 Nov 2011; Fig. 5c). Fourth, when EMUC core is shifted offshore as mentioned in the previous paragraph (03 Feb 2012; Fig. 5d). And fifth, the EMUC with two cores at the moment when it has its maximum transport (23 Dec 2012; Fig. 5e).

The latter snapshot shows a strong equatorward undercurrent concomitant with a strong poleward surface current, suggesting an important baroclinic component of the geostrophic system, since a purely baroclinic structure must present a vertical compensation of the flow in order to have zero net transport. On the other hand, Fig. 5b suggests an important poleward barotropic contribution, since a flow reversal in the vertical is virtually absent.

\subsection{Equatorward Volume Transport}

The first challenge involved in the calculation of the EMUC volume transport is to define the extrapolation methods to fill in the empty data regions (Fig. 2a). As detailed in Section 2, we use two opposite boundary conditions (no-slip and full-slip), as well as optimal interpolation to address this issue.

Subsequently, we have to define the limits where the flow across the transect will be computed as an undercurrent. A first choice might be to consider the flow enclosed by the $0 \mathrm{~m} \mathrm{~s}^{-1}$ isotach found at every moment. However, 

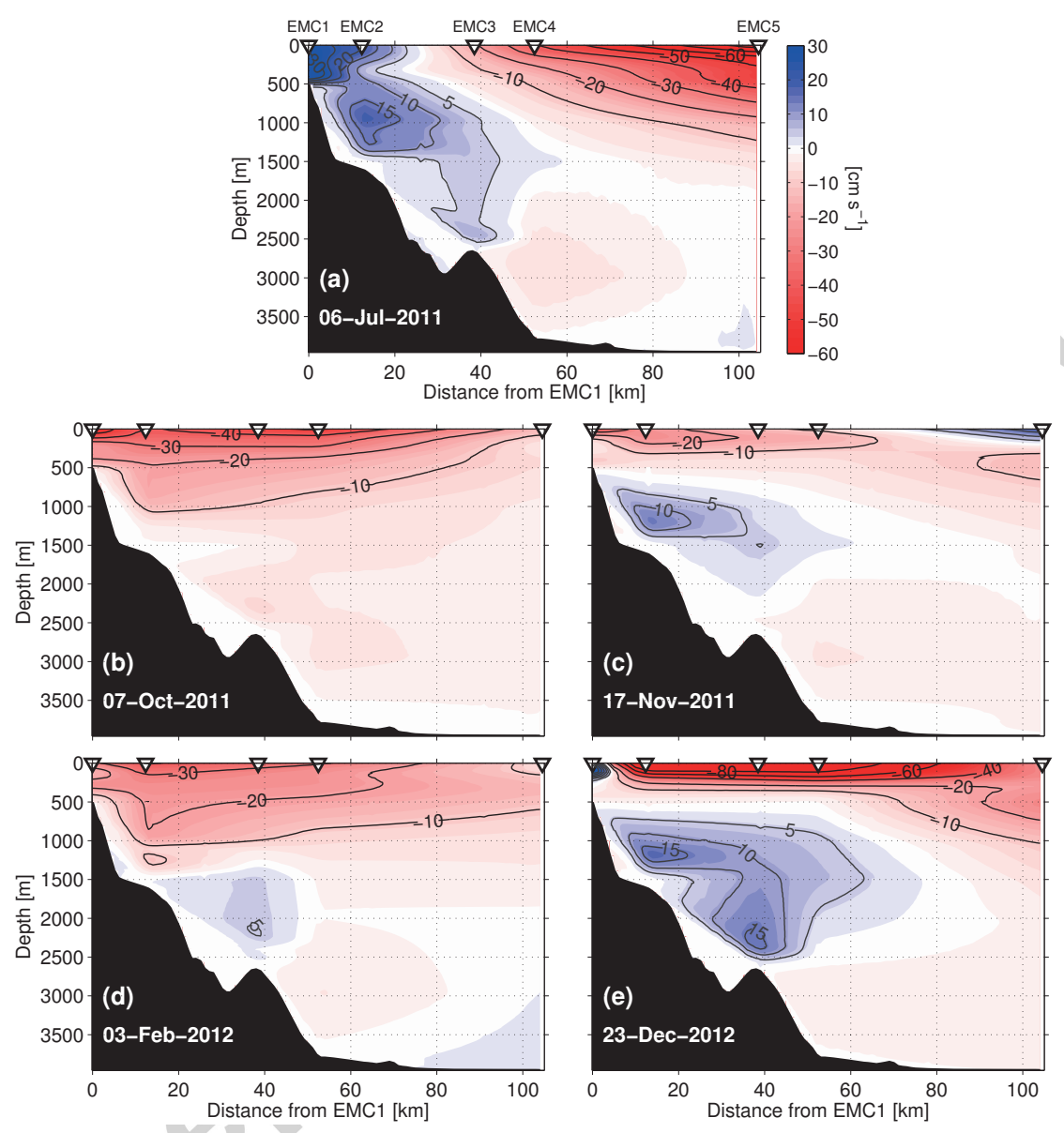

Figure 5: Alongshore velocities observed at five different moments: (a) EMUC flow reinforced by a cyclonic eddy (06 Jul 2011); (b) during the absence of equatorward flow (07 Oct 2011); (c) an undercurrent flowing with the primary intermediate core (17 Nov 2011); (d) occasion when only the secondary core is observed (03 Feb 2012), and (e) a strong EMUC (maximum transport), in which the flow exhibits the primary and deep secondary cores (23 Dec 2012). These snapshots are indicated in Fig. 4 by vertical dashed lines. Extrapolations to the coast were made through optimal interpolation. 
such a choice is not practical because the EMUC does not always appear well organized as a single "package", but either the zero velocity contour is spread all over the whole transect, or the undercurrent is merged with a poleward flow of different nature (for instance, Fig. 5a).

In this study we propose two methods to provide the EMUC transport time series: Equatorward Volume Transport (EVT) and Net Volume Transport (NVT). The first (presented in this Section 3.2) aims to quantify exclusively the amount of water transported equatorward by the undercurrent, and therefore only grid cells with positive velocities are used for this computation. Notice that transport values must be positive, so they do not necessarily have Gaussian statistics. The second method is addressed to access the transport variability and it is described in Section 3.3.

In order to calculate the EVT we first defined a rectangle (yellow dashed line in Fig. 3b) within which only grid cells with equatorward transport were computed for the total transport. On the east, the rectangle is bounded at a horizontal distance of $75 \mathrm{~km}$ from EMC1, to the west by the continental slope, and vertically by the levels of 750 and $3000 \mathrm{~m}$. To delimit these boundaries, we took into account the average flow (Fig. 3b), cases of deeper and offshore undercurrent excursions observed in the time series and the EMUC boundaries presented in the literature (Fig. 3 from Nauw et al. (2008)).

Fig. 6a exhibits the EVT independently calculated from the three different extrapolation methods. Average transports (and standard deviations) of 1.23 $( \pm 1.31), 1.54( \pm 1.61)$ and $1.23( \pm 1.30) \mathrm{Sv}$ were found for no-slip, full-slip and optimal interpolation, respectively. If the mean of the three methods is taken, the transport amounts to $1.33( \pm 1.41) \mathrm{Sv}$. This value is equivalent to 
$7 \%$ of the EMC mean transport, estimated to be $\sim 18.5 \mathrm{~Sv}$ from our data or 20.5 Sv from the literature (Swallow et al., 1988; Schott et al., 1988). A peak in the EMUC transport higher than $6.5 \mathrm{~Sv}(6.86,8.50$ and $6.80 \mathrm{~Sv}$, at the same extrapolation order) occurred in the transition spring-summer in 2012 .

There are moments when the EVT dropped to zero due to poleward reversals of the flow. These "flats" (e.g. January 2011, Fig. 6a) affect the time series oscillations and consequently the periodogram analysis. In order to identify significant period bands, another way to access the transport is presented in the next section.

\subsection{Net Volume Transport}

Net Volume Transport has been computed taking into account both equatorward and poleward flows crossing a fixed area enclosed by the average $0 \mathrm{~m}$ $\mathrm{s}^{-1}$ isotach (green line in Fig. 3b). Note that this method is not appropriate to quantify the volume of water transported northward by the undercurrent (as proposed in the previous section), since it underestimates the transport in case of a spread-out undercurrent. Also, because poleward velocities are generally much stronger than equatorward velocities (compare the colorbar scale in Fig. 3b and Fig. 5), we could not use the same rectangle defined in the previous section to calculate the NVT, otherwise the resulting transport in this region (rectangle) would be poleward and, consequently, the EMUC equatorward transport would be masked.

Fig. $6 \mathrm{~b}$ shows the NVT time series, where the average value from the three extrapolation methods is $0.21( \pm 1.25) \mathrm{Sv}$, while the maximum is 3.93 Sv. Seasonal averages show that occasionally the transport was marked by 

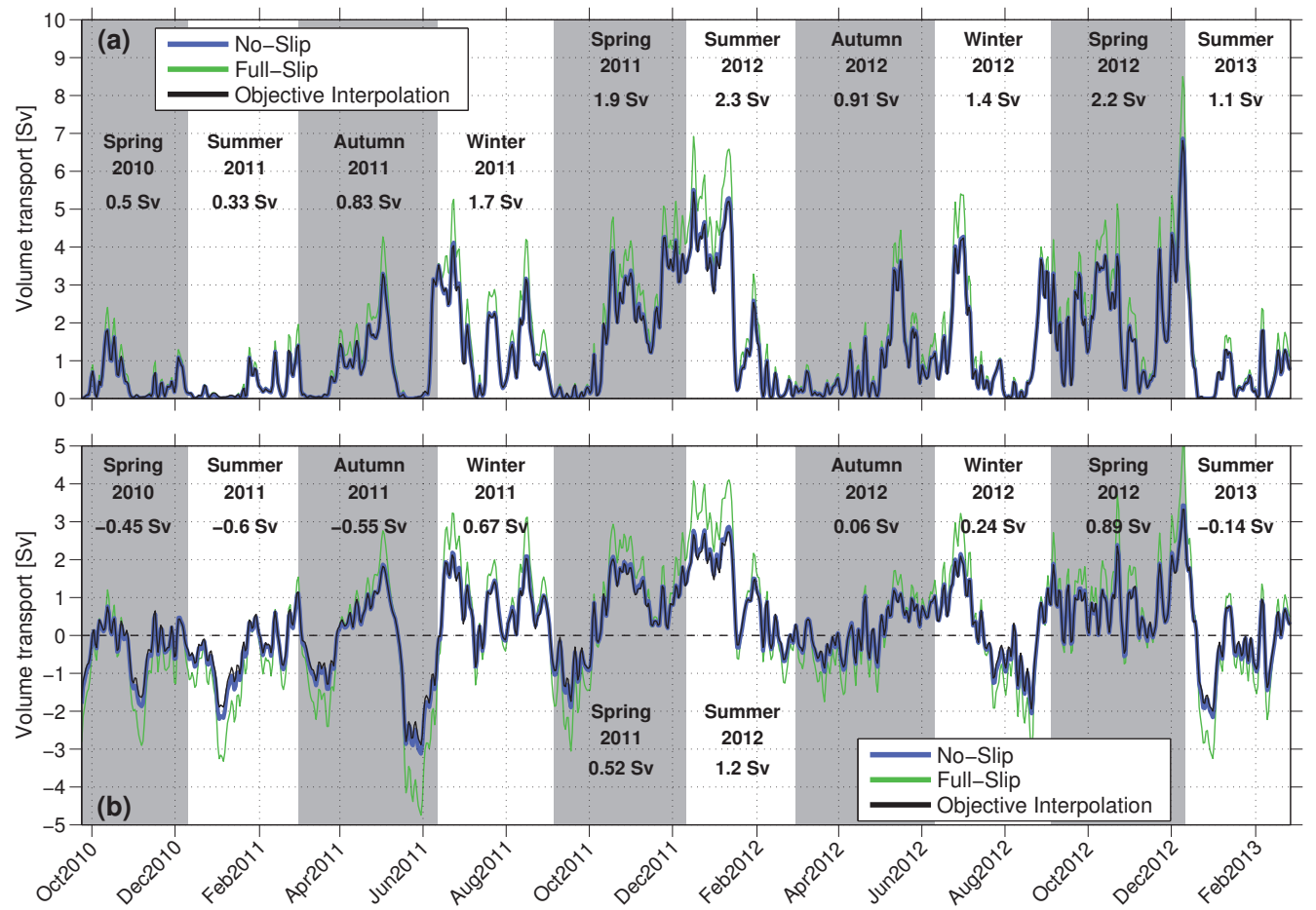

Figure 6: (a) Equatorward Volume Transport (EVT): only grid points with positive velocities from the area delimited by the yellow rectangle shown in Fig. 3b were computed. (b) Net Volume Transport (NVT): all values (positive and negative) at grid points inside the region enclosed by the average $0 \mathrm{~m} \mathrm{~s}^{-1}$ isotach (green line in Fig. 3b) were computed. In both cases the transport was estimated through three different gridding methods: no-slip (blue line), full-slip (green line) and optimal interpolation (black line). Note that blue and black lines almost overlap. The gray and white vertical bars display the mean volume transport in every season.

poleward net transport, for instance, during Spring-2010, Summer-2011 and Autumn-2011 (vertical bars in Fig. 6b). But, this fact does not mean that there was a predominance of the poleward flow over time. For instance, in Spring-2010 there were more days with equatorward flow, but the mean is 
still negative (poleward flow). This flow reversal is associated with a deep excursion of the EMC, in which velocities are much larger than in the EMUC.

Overall, both EVT and NVT time series present the same pattern of variability (Figs. 6a,b), except during events of reversal of the flow when the NVT also has negative values (Fig. 6b).

\subsection{Variability}

A large amount of variability about the mean occurs on different time scales, both in transport and velocity. Such variability may be induced by different factors: current meandering, actual reductions in the water volume carried by the current, eddy interactions and spatial amplification of the flow are some examples. Our time series reveal that the interaction of all these factors affects the EMUC. In the light of this, an important question emerges: is the EMUC variability dominated by particular frequency bands?

This question is answered affirmatively by means of wavelet analysis (Torrence and Compo, 1998), applied both to the velocity (Figs. 7a-d,f) and the NVT time series (Figs. 7e,g).

The velocity series from EMC3 (Figs. 7b-d) show a persistent nearly semiannual period centered around 160 days (frequency of 2.3 year $^{-1}$ ), which dominates when integrated over time (Fig. 7f). In addition, for the same three EMC3 time series, secondary peaks around a nearly bi-monthly period band are identified, although they are not persistent over the entire time span. Different from that observed for the nearly semi-annual period, the nearly bi-monthly peaks are not positioned at exactly the same time-period (Fig. 7f).

The velocity time series near the EMUC core, extracted from the bottom 
ADCP moored at EMC2, revealed only a strong nearly bi-monthly period band centered around 66 days (frequency of 5.5 year $^{-1}$ ), although it is also non-persistent over the whole time span. For example, from March to October 2012, such a period was not significantly present. No trace has been found of the nearly semi-annual period in this time series (see red lines in Figs. 7a,f).

Considering the NVT time series, the wavelet analysis shows both nearly semi-annual (strongest) and nearly bi-monthly peaks (Figs. 7e,g).

To better define the nearly bi-monthly and nearly semi-annual band periods, we considered all points in the global power spectra in which the values are over the $95 \%$ significance level (part of the curve to the right of the corresponding dashed line in Fig. 7g). Results show intervals of 46-79 days and 132-187 days, respectively. These two band periods are highlighted by the gray horizontal bars in Figs. 7f-g.

Beal (2009) also found the nearly bi-monthly period for the Agulhas Undercurrent. This author related this frequency band to the same mode that dominates the main surface Agulhas Current variability, an assessment that we share and, analogously, link the EMUC nearly bi-monthly period to the surface EMC variability (Schott et al., 1988). Such a variability in the EMC domain is attributed to the barotropic mode, forced by local wind-stress curl over the Mascarene Basin (Matano et al., 2002; Warren et al., 2002; Weijer, 2008).

The origin of the nearly semi-annual cycle seems to be associated with the monsoon wind regime, which is pronounced over the eastern equatorial Indian Ocean, and marked by a strong semi-annual cycle. However, there is no clear 

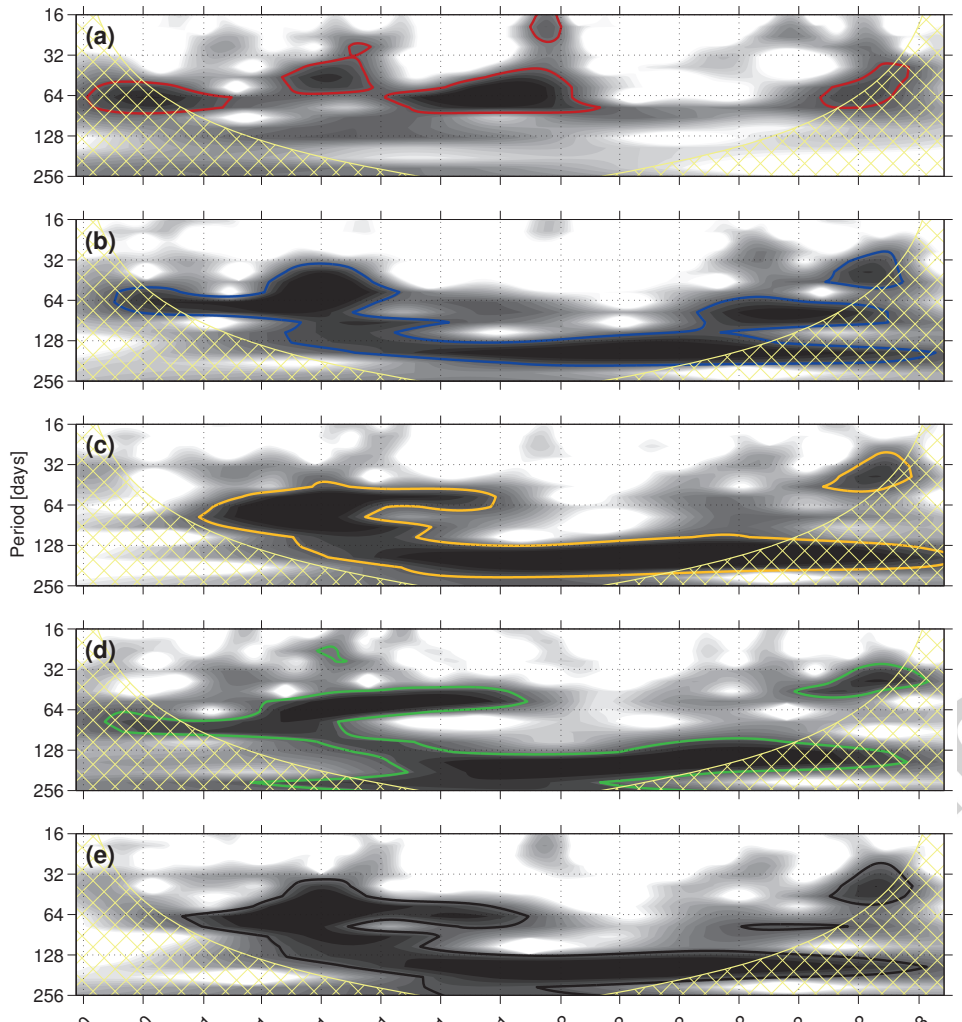

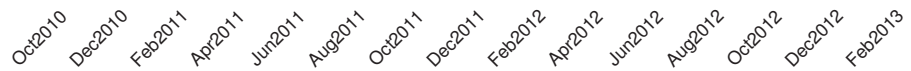

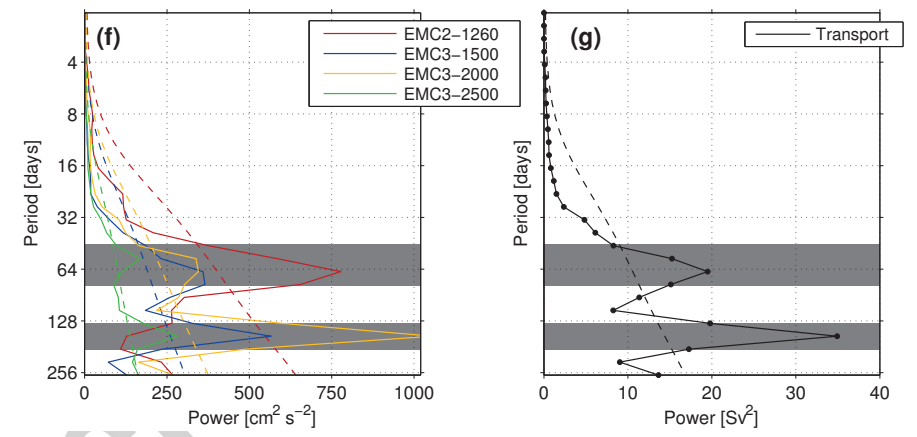

Figure 7: Wavelet power spectra of alongshore velocities and volume transport time series: (a) EMC2-1260; (b) EMC3-1500; (c) EMC3-2000; (d) EMC3-2500; (e) Net Volume Transport (NVT). The colored contours (red, blue, yellow, green and black, respectively) denote the $95 \%$ significance levels above a red noise background spectrum, while the crosshatched areas indicate the "cone of influence" where edge effects become important. For all cases the mother wavelet is Morlet wavelet (see Torrence and Compo (1998) for details). Global power spectra for alongshore velocities (f) and NVT (g) time series. For every series, the dashed lines correspond to the $95 \%$ significance levels. Nearly bi-monthly period (46-79 days) and nearly semi-annual period (132-187 days) are represented by the horizontal gray bars. 
understanding on how this signal propagates to the western boundary and manifest itself in the EMUC at $23^{\circ} \mathrm{S}$.

Morrow and Birol (1998) showed that baroclinic Rossby waves are generated near the Indian Ocean eastern boundary, extending across the entire basin, between $20^{\circ} \mathrm{S}$ and $35^{\circ} \mathrm{S}$, with characteristic timescales between 120 and 180 days. Such timescales are in a good agreement with the nearly semi-annual cycle (132-187 days) here defined.

Schouten (2001) and Schouten et al. (2002) proposed an explanation for the adjustment of the western part of the basin to the monsoon regime. According to these authors, Kelvin waves generated in the equatorial region are observed to reach the west coast of Indonesia, after the reversal of monsoons, from where they propagate southward as coastal Kelvin waves, so that these waves work as a trigger for Rossby waves at midlatitudes. But, the authors also speculated that the reflection of semi-annual Rossby waves against the Maldives ridge, near the middle of the basin, are frequency doubled and then arrive at the western boundary with a frequency of 4 per year. Therefore, care should be taken in definitely relating monsoon regimes to EMUC semiannual variability. Due to the regional focus of this paper, a detailed study of basin scale processes still has to be conducted to confirm (or reject) such a teleconnection.

Fig. 8 shows a bandpass filter (forward-backward Butterworth filter) of the NVT time series with the passband adjusted for the nearly semi-annual and nearly bi-monthly periods, conjointly to the sum of both, plotted together with the original transport time series. The nearly bi-monthly, nearly semi-annual and the composition of both explain, respectively, about $21 \%$, 
$27 \%$ and $48 \%$ of the transport variance.

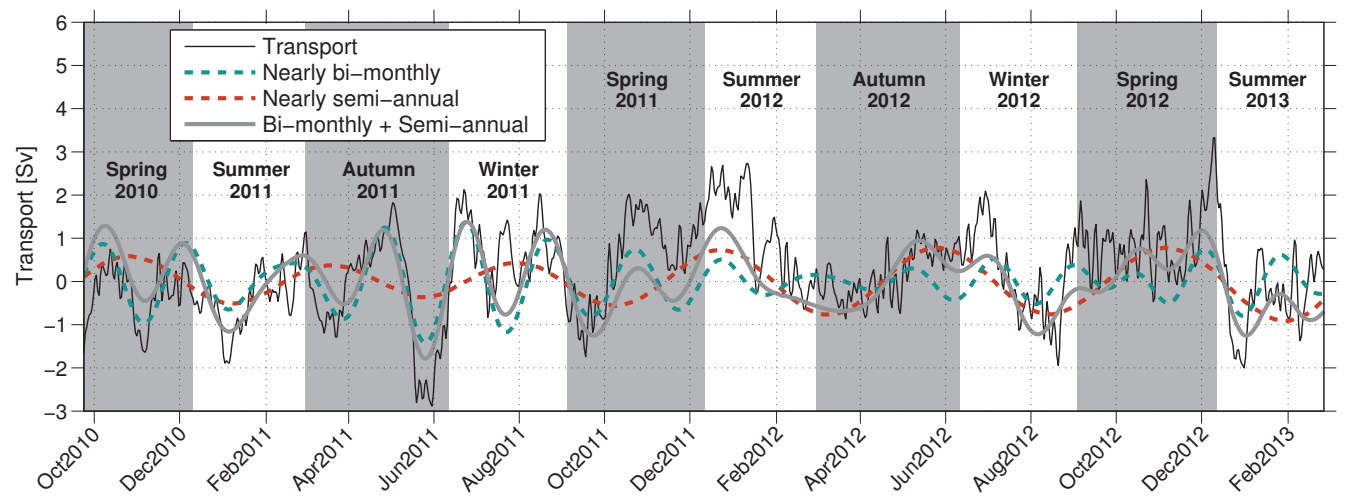

Figure 8: Bandpass filter of the detrended Net Volume Transport (NVT) time series (black solid line) considering the nearly bi-monthly (46-79 days, dashed blue line) and nearly semi-annual (132-187 days, dashed red line) periods. The gray line shows the composition of the two periods.

In order to illustrate whether or not some seasonal patterns appear in the volume transport, Table 2 summarizes the EVT in every season, as previously highlighted by the vertical bars in Fig. 6a. Averages of 1.24, 0.87, 1.57 and 1.59 Sv have been found for summer, autumn, winter and spring, respectively. A reduced mean transport occurred in autumn, while maxima occurred in spring and winter. But, the wavelet spectral analysis did not show a significant seasonal variability.

If averages of two subsequent seasons are considered, transports of 1.42 (spring-summer), 1.09 (summer-autumn), 1.22 (autumn-winter) and $1.58 \mathrm{~Sv}$ (winter-spring) suggest a stronger undercurrent during winter-spring compared to summer-autumn. But, this association must be interpreted with caution, since a longer time series must be considered. 
Table 2: Average seasonal Equatorward Volume Transport (EVT) and variance for every season and for two subsequent seasons. The averages are calculated through a mean between series from the three different extrapolation methods.

\begin{tabular}{cccc}
\hline Period & \# days & Mean transp. $(\mathrm{Sv})$ & Variance $\left(\mathrm{Sv}^{2}\right)$ \\
\hline Summer & 260 & 1.24 & 2.88 \\
Autumn & 186 & 0.87 & 0.85 \\
Winter & 188 & 1.57 & 1.61 \\
Spring & 254 & 1.59 & 1.89 \\
Spring-Summer & 514 & 1.41 & 2.42 \\
Summer-Autumn & 446 & 1.09 & 2.06 \\
Autumn-Winter & 374 & 1.22 & 1.35 \\
Winter-Spring & 442 & 1.58 & 1.77 \\
\hline
\end{tabular}

There is a difference in the mean EVT between 2011 (1.2 Sv) and 2012 $(1.7 \mathrm{~Sv})$, suggesting also an interannual mode of variability of the system. Interannual variability has already been identified in the SWIO, for instance, inside the Mozambique Channel (Harlander et al., 2009; Ridderinkhof et al., 2010; Ullgren et al., 2012). Unfortunately, the length of our time series does not allow us to study this phenomenon in depth.

\section{On the EMUC baroclinic/barotropic partitioning}

The partitioning of velocity profiles in barotropic and baroclinic components is addressed in this section. We use a simple barotropic/baroclinic decomposition where the barotropic component is interpreted as the vertical 
average of the alongshore velocity profile, while the remaining sheared profile represents the baroclinic component (da Silveira et al., 2004; Meinen et al., 2013). Fig. 9 shows two examples where the alongshore velocity fields are decomposed in barotropic and baroclinic fields. Such a partitioning is applied to the entire time span, at each horizontal grid point and at every moment.

Fig. 9a shows a case where a robust poleward barotropic flow is extracted from the observed field. At this moment the EMC migrates deep into the water column (the $-10 \mathrm{~cm} \mathrm{~s}^{-1}$ isotach reaches about $1500 \mathrm{~m}$ ), inhibiting the equatorward flow at intermediate levels, and as consequence the undercurrent is not observed in the data at this moment, although its baroclinic signal is still present. Fig. 9b shows a situation when the barotropic influence is reduced, and therefore the baroclinic field is similar to the observed.
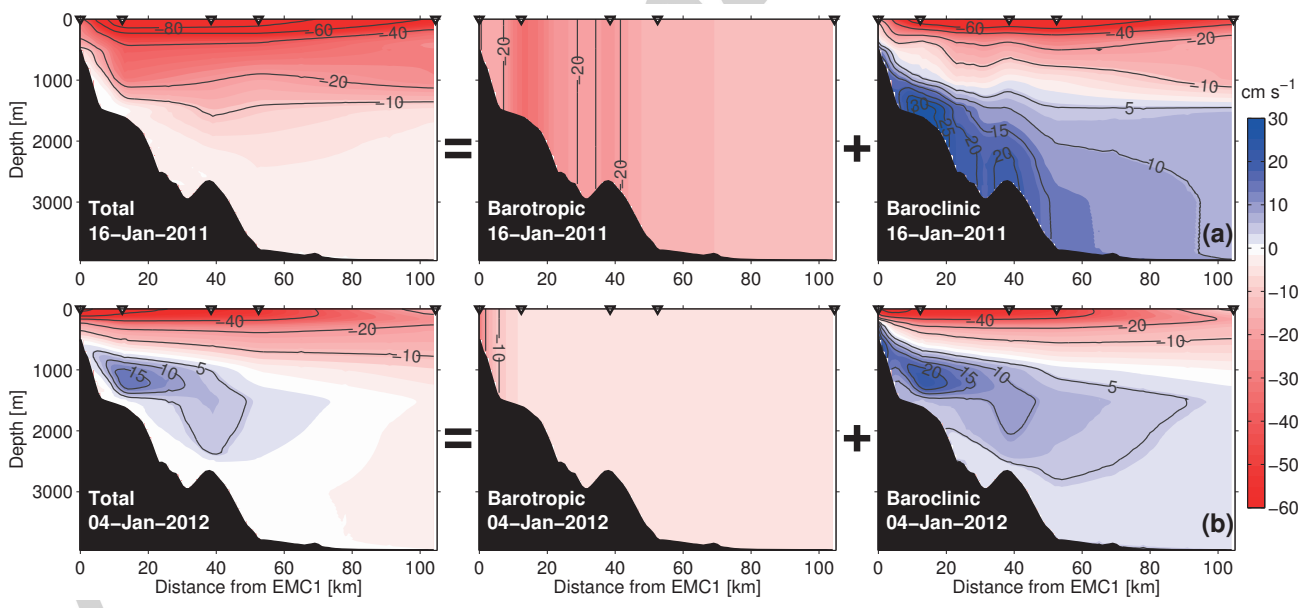

Figure 9: Observed alongshore velocity field (left), and its partitioning in barotropic (center) and baroclinic (right) fields, on (a) 16 Jan 2011 and (b) 04 Jan 2012.

Considering that the barotropic pressure gradients are forced at the surface, we investigate the cross-shore gradients of absolute dynamic topography 
$(\eta)$ from altimetry. While $\eta$ comprises both baroclinic and barotropic effects (Gill and Niiler, 1973; Rintoul et al., 2002), the latter is straightforward and constant from the surface to the bottom. So, one might wonder whether or not strong (positive) cross-shore gradients of $\eta(\partial \eta / \partial x)$ may correspond to a strong (negative) alongshore barotropic flow and, consequently, induce a weakening or reversal of the undercurrent speeds. Surface velocity is related with $\partial \eta / \partial x$ through geostrophy: $v=(g / f)(\partial \eta / \partial x)$, where $g$ is the acceleration due to gravity and $f$ is the Coriolis parameter $(f<0$ on Southern Hemisphere).

Distance-time diagrams of $\partial \eta / \partial x$, alongshore barotropic velocity $\left(v_{B T}\right)$, alogshore observed velocity at $1260 \mathrm{~m}(v(1260))$, and alongshore baroclinic velocity at $1260 \mathrm{~m}\left(v_{B C}(1260)\right)$ are shown in Figs. 10a-d. Notice that $v_{B T}$ is persistently negative (Fig. 10b), forcing a flow against the EMUC. Its strong events are mainly associated with strong positive $\partial \eta / \partial x$. There is only one moment when a remarkable reversal of the barotropic flow is observed: during the reported cyclonic eddy (around 6 Jul 2011). On the other hand, the baroclinic signal at $1260 \mathrm{~m}$ is persistently equatorward (Fig. 10d), although it is superimposed by stronger barotropic events (Fig. 10c).

Time series extracted from the EMC2 location are plotted in Figs. 10e,f, while Table 3 exhibits the correlation coefficients calculated between every pair of variables throughout the whole time span. Overall, the results confirm that a strong negative $v_{B T}$ is related with a strong positive $\partial \eta / \partial x$, leading to attenuation or reversal of the flow in the EMUC. But not always a strong $\partial \eta / \partial x$ leads to a strong $v_{B T}$ (for instance, Jan/2012).

We also computed the correlation coefficients with a moving window of 

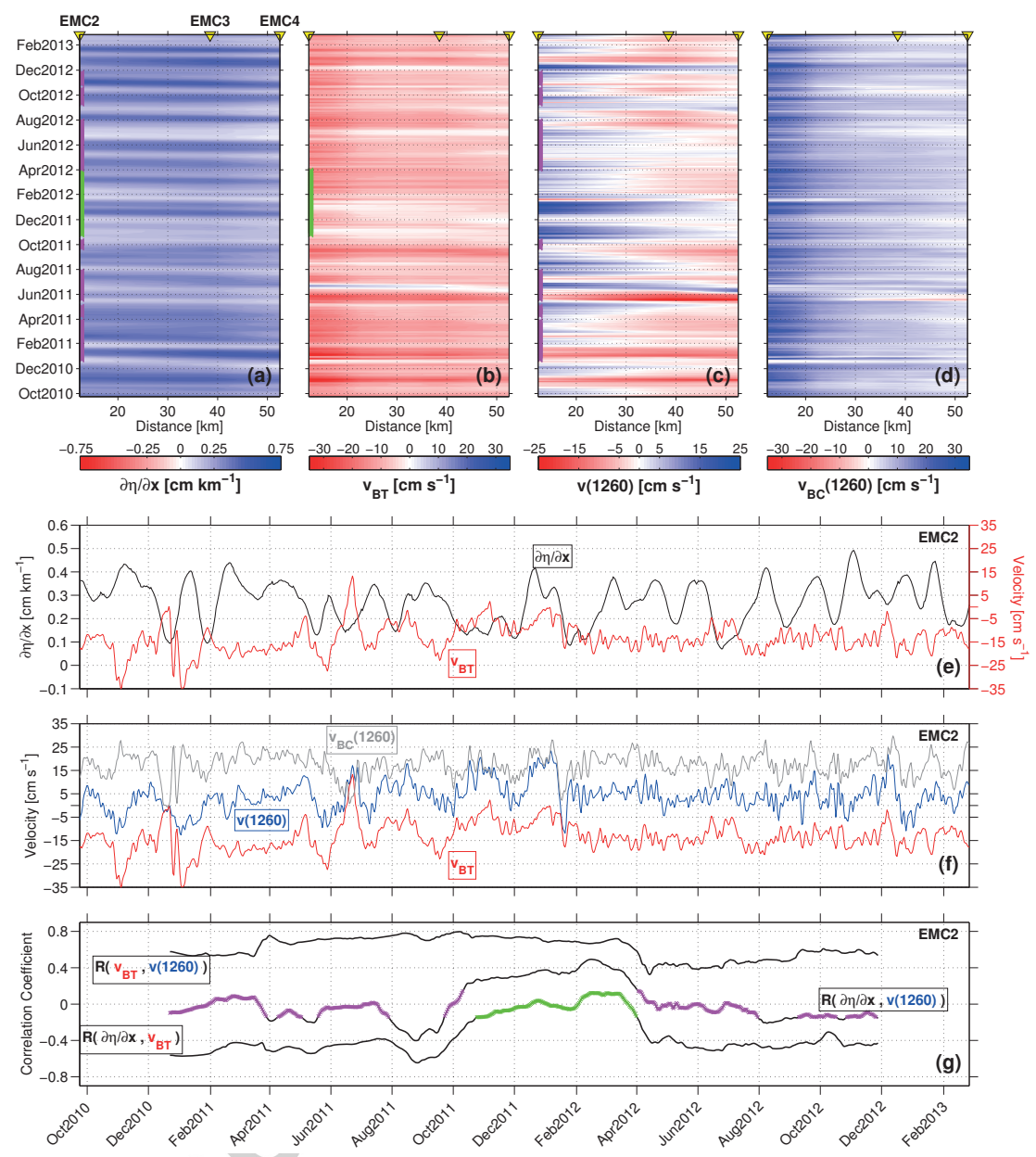

Figure 10: Distance/time diagrams: (a) horizontal gradients of absolute dynamic topography $(\partial \eta / \partial x)$, interpreted in terms of a finite difference $\Delta \eta / \Delta x$; (b) alongshore barotropic velocity $\left(v_{B T}\right)$; (c) alongshore observed velocity at $1260 \mathrm{~m}(v(1260))$; and $(\mathrm{d})$ alongshore baroclinic velocity at $1260 \mathrm{~m}\left(v_{B C}(1260)\right)$. (e) Time series at the EMC2 location of $\partial \eta / \partial x$ (black line and left y-axis) compared to $v_{B T}$ (red line and right $\mathrm{y}$-axis). (f) Time series at the EMC2 location of $v(1260)$ (blue line) and $v_{B C}(1260)$ (gray line) compared to $v_{B T}$ (same than (d); red line). (g) Correlation coefficients (R) computed with a moving window of 180 days between $\partial \eta / \partial x, v_{B T}$ and $v(1260)$ time series. The pink and green line segments highlight no significant correlations (p-value test). These points are time-projected on the plots (a), (b) and (c). 
Table 3: Correlation coefficients (R) computed at EMC2 location between every pair of the following variables: $\partial \eta / \partial x, v_{B T}, v(1260) v_{B C}(1260)$. All correlations are significant (p-test value) for a $95 \%$ confidence level.

\begin{tabular}{ccccc}
\hline & $\partial \eta / \partial x$ & $v_{B T}$ & $v(1260)$ & $v_{B C}(1260)$ \\
\hline$\partial \eta / \partial x$ & 1.00 & & & \\
$v_{B T}$ & -0.44 & 1.00 & & \\
$v(1260)$ & -0.11 & 0.68 & 1.00 & \\
$v_{B C}(1260)$ & 0.42 & -0.41 & 0.40 & 1.00 \\
\hline
\end{tabular}

180 days (similar to the nearly semi-annual period). The results show that such a correspondence can be stronger or not significant (Fig. 10g), depending on the moments of the time series. For instance, in the period from Nov/2011 to Apr/2012 (green segment) the correlation between $\partial \eta / \partial x$ and $v_{B T}$ is not significant.

Around Jan/2012, both EMUC $(v(1260))$ and $\partial \eta / \partial x$ are marked by strong events and, therefore, a significant positive correlation is observed between these two time series. We do not have a clear explanation for this observation.

\section{Spatial extent and thermohaline properties from Argo floats}

The time series studied in previous sections present results in the matter of continuous long-term observations of the EMUC. Nevertheless, the data are restricted to a certain latitude $\left(\sim 23^{\circ} \mathrm{S}\right)$. Uncertainty about the extent of the undercurrent farther north and the spatial variation of the thermohaline 
properties in its domain could not be investigated with the INATEX data. In order to address those issues we use a historical dataset of Argo profiling floats.

\subsection{Spatial extent}

The origin of the EMUC seems to be placed at the continental slope near the southern tip of Madagascar (Nauw et al., 2008). These authors showed (in their Figure 3) four frames where the undercurrent transport is increasing from a meridional transect at $45^{\circ} \mathrm{W}$, located slightly west to the southern tip of the island, to the southeastern coast of Madagascar.

In Figs. 11a,b, we show the vectors of horizontal velocity from the ANDRO database (Ollitrault and Rannou, 2013), derived at the surface and near $1000 \mathrm{~m}$ depth (Argo "parking" depth), respectively. Most of the floats north of $21^{\circ} \mathrm{S}$ and near the slope were captured by the equatorward undercurrent (Fig. 11b, blue vectors), even taking into account that their parking depth is near the region of the mean flow reversal (see $0 \mathrm{~m} \mathrm{~s}^{-1}$ isotach in Fig. 3b).

Farther downstream, Argo-derived velocities suggest an equatorward undercurrent flowing until approximately $17^{\circ} \mathrm{S}$, the region where the South Equatorial Current bifurcates towards the Madagascar coast (Swallow et al., 1988; Chapman et al., 2003; Siedler et al., 2006). No floats were caught by the undercurrent south of $21^{\circ} \mathrm{S}$, which might be due to upstream deepening of the undercurrent.

It is important to note that even floats with poleward displacements (red vectors in Figs. 11a,b) could have profiled the undercurrent south of $21^{\circ} \mathrm{S}$, since these autonomous devices descend to $2000 \mathrm{~m}$ during the vertical profiling. Nevertheless, the blue vectors in Fig. 11b corroborate the results from 
the time series (see Fig. 3b) and indicate a region where the EMUC is expected to occur, in between the isobaths of 1000 and $3000 \mathrm{~m}$.

\subsection{Thermohaline properties at intermediate levels}

In this section we investigate the thermohaline properties around Madagascar Island at intermediate levels. Intermediate waters are generically defined to lie in the isopycnal range of $26.9-27.7 \mathrm{~kg} \mathrm{~m}^{-3}$ in the SWIO (Donohue and Toole, 2003). The EMUC, in turn, has been found in between the isopycnals of 27.2 and $27.75 \mathrm{~kg} \mathrm{~m}^{-3}$ at $25^{\circ} \mathrm{S}$ (Nauw et al., 2008).

Based on thermohaline, oxygen and nutrient data, Nauw et al. (2008) conducted a water mass analysis that shows a contrast between a saline water mass near the EMUC core and a fresher one around the offshore border of the undercurrent. The fresher water was due to the strong contribution of Antarctic Intermediate Water (AAIW), which is marked by a minimum in salinity. On the other hand, these authors related the increase of salinity towards the continental slope to the influence of the poorly oxygenated Red Sea Water (RSW). However, these previous results are based on four quasi-synoptic transects around the southern tip of Madagascar and, hence, there is no information whether this cross-shore salinity gradient is persistent northward to $25^{\circ} \mathrm{S}$, along the eastern margin of the island.

The RSW pathway tracked by those authors is the following: RSW emerging from the Gulf of Aden is partially diluted and transported southward at intermediate levels inside the Mozambique Channel (Wyrtki, 1971; Beal et al., 2000). Somehow it contours the southern tip of Madagascar Island and, leaning on the continental slope, the diluted RSW forms the EMUC core. In turn, AAIW is known to spread northward after being injected in 

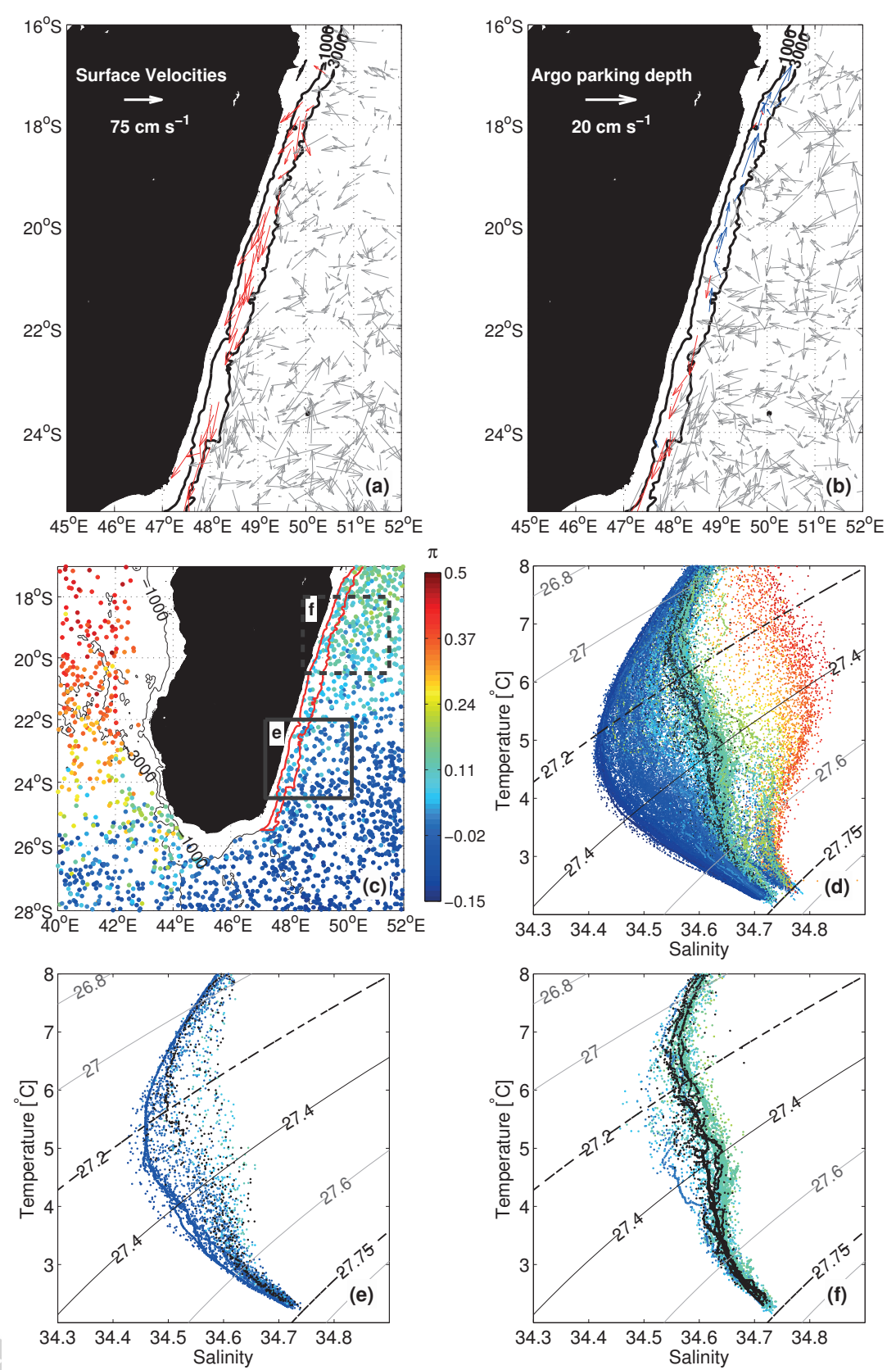

Figure 11: ANDRO current velocities deduced at (a) surface and (b) near the Argo parking depth $(\sim 1000 \mathrm{~m})$. (c) Spiciness $(\pi)$ at the isopycnal level of $27.4 \mathrm{~kg} \mathrm{~m}^{-3}$ estimated from historical Argo profiles. (d) $\theta$-S diagram corresponding to the Argo profiles used in (c). The same spiciness colors used in (c) are used in (d) so only to stress the geographical position of the profiles. Profiles sampled in the region enclosed by the red line along the slope (bounded by the 1000 and $3000 \mathrm{~m}$ isobaths) are plotted in black. (e-f) $\theta$-S diagram for the profiles enclosed by the (e) solid and (f) dashed rectangles highlighted in (d), respectively. Black profiles represent the same as in (d). 
the southwestern portion of the basin, around $50-60^{\circ} \mathrm{E}$, north of the Kerguelen Plateau $\left(\sim 50^{\circ} \mathrm{S}\right)$ (Park et al., 1993; Donohue and Toole, 2003).

Fig. 11c shows the spiciness $(\pi)$ at the isopycnal level of $27.4 \mathrm{~kg} \mathrm{~m}^{-3}$ estimated from historical Argo profiles, according to the algorithm developed by Flament (2002). Spiciness is a state variable useful to characterize water mass, with largest (smallest) values corresponding to hot-and-warm (coldand-fresh) waters. The results reproduce the pathway of the diluted RSW described above. Waters marked by high spiciness values are found in the north portion of the Mozambique Channel, while low spiciness waters are found offshore to the southeast of Madagascar.

Fig. 11d shows the $\theta$-S diagram plotted with the same profiles used to estimate the spiciness displayed in Fig. 11c. We also use the same spiciness colors so only to distinguish the $\theta$-S profiles according to their geographical position. Additionally, profiles sampled in the region where the EMUC is expected to occur (area bounded by the red line in Fig. 11c) are plotted in black.

Notice in Fig. 11e that the $\theta$-S diagram, from the region off the southeastern coast (solid rectangle in Fig. 11c, northward-limited at $22^{\circ} \mathrm{S}$ ), reinforces that waters in the EMUC region are saltier than waters offshore. On the other hand, this cross-shore salinity gradient is not observed in the $\theta$-S diagram from the profiles sampled off the eastern coast (dashed rectangle in Fig. 11c, southward-limited at $20.5^{\circ} \mathrm{S}$ ), as can be seen in Fig. 11f. These results suggest that the zonal gradient of salinity found by Nauw et al. (2008) at $25^{\circ} \mathrm{S}$ vanishes northward, while the influence of AAIW also vanishes in the same direction. 


\section{Discussion and Conclusions}

As part of the Southern Hemisphere supergyre (de Ruijter, 1982), the western boundary current system in the South-West Indian Ocean (SWIO) is a remarkable component of the thermohaline circulation and global climate through the Indian-Atlantic interocean exchange (Beal et al., 2011). In this scenario, the East Madagascar Current (EMC) is one of the main sources of the Agulhas Current and seems to impact downstream the variability of the Agulhas retroflection via southward propagating dipoles (de Ruijter et al., 2004; Ridderinkhof et al., 2013).

The East Madagascar Current system itself is composed of the surface poleward EMC and an underlying flow at intermediate levels, near the continental slope, associated with the East Madagascar Undercurrent (EMUC). The existing information describing the EMUC is based on a few quasisynoptic measurements (Nauw et al., 2008).

In this work, we extend previous results to a long-term description of the EMUC based on 2.5 years of velocity observations, along a line of 5 moorings deployed at $23^{\circ} \mathrm{S}$, sampled in the scope of the "INdian-ATlantic EXchange in present and past climate" (INATEX) project. Furthermore, altimeter data and Argo data (temperature-salinity and horizontal velocity) were also used.

Direct velocity measurements from the INATEX array reveal a recurrent EMUC which was present $78 \%$ of the sampling time (692 from 888 days). Some of the reversal periods were directly associated with a strong barotropic component of the poleward western boundary current. The maximum equatorward velocity reached $27.3 \mathrm{~cm} \mathrm{~s}^{-1}$ in the mooring EMC2 $(28.6 \mathrm{~km}$ from the coast) at a depth level of $1110 \mathrm{~m}$, whereas maximum averaged velocity 
$\left(4.1 \mathrm{~cm} \mathrm{~s}^{-1}\right)$ was identified at around $1260 \mathrm{~m}$ at the same mooring. Mesoscale activities such as meandering and passage of a cyclonic eddy were also observed.

In this study we propose two methods to provide the EMUC transport time series: Equatorward Volume Transport (EVT) and Net Volume Transport (NVT). The first (EVT) is more appropriated for estimating the amount of water transported equatorward by the EMUC, and it computes only positive velocities enclosed in the area indicated by the yellow dashed line in in Fig. 3b. On the other hand, the second (NVT) is more suitable to address the transport variability. It accounts for both positive and negative velocities in the region enclosed by the mean $0 \mathrm{~m} \mathrm{~s}^{-1}$ isotach (green line in Fig. 3b). For the EVT case, maximum values can reach up to $6 \mathrm{~Sv}$ while the mean was about $1.33( \pm 1.41) \mathrm{Sv}$. The NVT presents average values of $0.21( \pm 1.25) \mathrm{Sv}$ and maxima of $3.93 \mathrm{~Sv}$.

Variability in two period bands showed up in the wavelet spectra of the NVT time series: nearly bi-monthly (46-79 days) and nearly semi-annual (132-187 days), which explain about $21 \%$ and $27 \%$ of the EMUC transport variance, respectively.

The nearly bi-monthly period is connected to the same mode that dominates the main EMC (Schott et al., 1988). In the literature this cycle is attributed to the incidence of barotropic Rossby waves originated due to local wind-stress curl over the Mascarene Basin (Matano et al., 2002; Warren et al., 2002; Weijer, 2008). Considering the velocity time series, the nearly bi-monthly period also showed up in the entire water column at the moorings EMC2 and EMC3. 
In turn, the nearly semi-annual cycle seems to be related to the monsoon wind regime over the eastern equatorial Indian Ocean. However, there is no theoretical understanding on how this signal propagates to the other side of the basin, and how it manifests itself in the EMUC at $23^{\circ} \mathrm{S}$. A suggestion is proposed by Morrow and Birol (1998), who observed baroclinic Rossby waves to be generated near the Indian Ocean eastern boundary, with a timescale between 120 and 180 days, and propagating westward across the whole basin in the range from $20^{\circ} \mathrm{S}$ to $35^{\circ} \mathrm{S}$.

Interannual variabilities could not be attempted due to the length of our time series, although a significant difference in transport was found between 2011 and 2012.

A partitioning of the alongshore velocity fields in barotropic and baroclinic contributions shows the baroclinic undercurrent as a persistent feature throughout time. But, sometimes the equatorward baroclinic component is masked by a relatively stronger barotropic flow, leading to reversals of the EMUC flow during these events. In turn, events of strong poleward barotropic velocities are often observed concomitantly with strong positive cross-shore gradients of absolute dynamic topography $(\partial \eta / \partial x)$, although not always a strong $\partial \eta / \partial x$ represents an increase of the barotropic flow.

Horizontal velocities from the ANDRO database indicate the extent of the EMUC farther north along the continental slope, which reaches approximately $17^{\circ} \mathrm{S}$.

An updated historical dataset of temperature-salinity Argo profiles was used to investigate the spatial variability of spiciness at intermediate levels, around the island of Madagascar. Results support previous observations 
reported by Nauw et al. (2008) at $25^{\circ} \mathrm{S}$, where the undercurrent core was found saltier than offshore waters, due to the contribution of diluted Red Sea Water (RSW) from the Mozambique Channel. However, we also show that this zonal salinity gradient vanishes equatorward, since the contribution of Antartic Intermediate Water (AAIW) also vanishes in that direction.

Results suggest that further research is still needed to improve our understanding of the EMUC. Uncertainty about whether an upstream shallowing of the undercurrent takes place, and whether the undercurrent interacts with the Equatorial Current system, requires future work based on in situ velocity measurements at northern latitudes along the eastern margin of Madagascar. Also, long-term measurements of the thermohaline properties are necessary, so that the relationship between EMUC and water mass can be addressed synoptically.

\section{Acknowledgements}

The INATEX program was funded by: Netherlands Organization for Scientific Research (NWO), section Earth and Life Sciences (ALW), through its grant no. 839.08.431. We thank the crew and technicians of the FRS Algoa and all who participated in the ACSEX cruises. J. Ullgren and W. de Ruijter are gratefully acknowledged for discussions and suggestions about the data processing and scientific contents, respectively. The altimeter products were produced by Ssalto/Duacs and distributed by Aviso with support from Cnes. ANDRO database were produced by Laboratoire de Physique des Oceans, Infremer. Argo thermohaline profiles were available through the Global Argo Data Repository of the National Oceanographic Data Center (NODC). The 
first author is grateful to "Coordenação de Aperfeiçoamento de Pessoal de Nível Superior" (CAPES), Brazil, for the concession of a grant. We thank three anonymous reviewers for their valuable contributions that allowed us to improve the manuscript substantially.

\section{References}

Beal, L. M., 2009. A time series of Agulhas Undercurrent transport. J. Phys. Oceanogr. 39, 2436-2450.

Beal, L. M., Bryden, H. L., 1997. Observations of an Agulhas Undercurrent. Deep-Sea Res. I 44 (9-10), 1715-1724.

Beal, L. M., de Ruijter, W. P. M., Biastoch, A., Zahn, R., 2011. On the role of the Agulhas system in ocean circulation and climate. Nature 472, 429-436.

Beal, L. M., Ffield, A., Gordon, A. L., 2000. Spreading of Red Sea Overflow Waters in the Indian Ocean. J. Geophys. Res. 105 (C4), 8549-8564.

Biastoch, A., Beal, L. M., Lutjeharms, J. R. E., Casal, T. G. D., 2009. Variability and coherence of the Agulhas Undercurrent in a high-resolution ocean general circulation model. J. Phys. Oceanogr. 39, 2417-2435.

Bryden, H. L., Beal, L. M., 2001. Role of the Agulhas Current in Indian Ocean circulation and associated heat and freshwater fluxes. Deep-Sea Res. I 48, $1821-1845$.

Carter, E. F., Robinson, A. R., 1987. Analysis models for the estimation of oceanic fields. J. Atms. and Ocean. Techn. 4, 49-74. 
Chapman, D. C., Lentz, S. J., 1997. Adjustment of stratified flow over a sloping bottom. J. Phys. Oceanogr. 27, 340-356.

Chapman, P., Marco, S. F. D., Davis, R. E., Coward, A. C., 2003. Flow at intermediate depths around Madagascar based on ALACE float trajectories. Deep-Sea Res. II 50, 1957-1986.

da Silveira, I. C. A., Calado, L., Castro, B. M., Cirano, M., Lima, J. A. M., Mascarenhas, A. S., 2004. On the baroclinic structure of the Brazil Current-Intermediate Western Boundary Current system at $22^{\circ}-23^{\circ} \mathrm{s}$. Geophys. Res. Lett. 31 (L14308), 1-5.

de Ruijter, W., 1982. Asymptotic analysis of the Agulhas and Brazil current systems. J. Phys. Oceanogr. 12, 361-373.

de Ruijter, W. P. M., Biastoch, A., Drijfhout, S. S., Lutjeharms, J. R. E., Matano, R. P., Pichevin, T., van Leeuwen, P. J., Weijer, W., 1999. IndianAtlantic interocean exchange: Dynamics, estimation, and impact. J. Geophys. Res. 104 (C9), 20885-20910.

de Ruijter, W. P. M., Ridderinkhof, H., Lutjeharms, J. R. E., Schouten, M. W., Veth, C., 2002. Observations of the flow in the Mozambique Channel. Geophys. Res. Lett. 29, 140-1-140-3.

de Ruijter, W. P. M., van Aken, H. M., Beier, E. J., Lutjeharms, J. R. E., Matano, R. P., Schouten, M. W., 2004. Eddies and dipoles around south Madagascar: formation, pathways and large-scale impact. Deep-Sea Res. I 51, 383-400. 
Donohue, K. A., Toole, J. M., 2003. A near-synoptic survey of the southwest Indian Ocean. Deep-Sea Res. II 50, 1893-1931.

Evans, D. L., Signorini, S. S., 1985. Vertical structure of the Brazil Current. Nature 315, 48-50.

Flament, P., 2002. A state variable for characterizing water masses an their diffusive stability: spiciness. Prog. Oceanogr. 54, 493-501.

Fomin, L. M., 1964. The Dynamic Method in Oceanography. Elsevier Publishing Company, Amsterdam, London and New York.

Gill, A. E., Niiler, P. P., 1973. The theory of the seasonal variability in the ocean. Deep-Sea Res. 20, 141-177.

Godfrey, J. S., Cresswell, G. R., Boland, F. M., 1980. Observations of low Richardson numbers and undercurrents near a front in the East Australian Current. J. Phys. Oceanogr. 10, 301-307.

Gordon, A. L., Weiss, R. F., Smethie Jr., W. M., Warner, M. J., 1992. Thermocline and intermediate water communication between the south Atlantic and Indian Oceans. J. Geophys. Res. 69, 97 (C5).

Harlander, U., Ridderinkhof, H., Schouten, M. W., de Ruijter, W. P. M., 2009. Longterm observations of transport, eddies, and Rossby waves in the Mozambique Channel. J. Geophys. Res. 114 (C02003), 1-15.

Hu, D., Cui, M., 1991. The western boundary current of the Pacific and its role in the climate. Chin. J. Oceanol. Limnol. 9, 1-14. 
Hu, D., Hu, S., Wu, L., Li, L., Zhang, L., Diao, X., Chen, Z., Li, Y., Wang, F., Yuan, D., 2013. Direct measurements of the Luzon Undercurrent. J. Phys. Oceanogr. 43, 1417-1425.

Lutjeharms, J. R. E., 2006. The Agulhas Current. Springer, Berlin.

MacCready, P., Rhines, P. B., 1993. Slippery bottom boundary layers on a slope. J. Phys. Oceanogr. 23, 5-22.

Matano, R. P., Beier, E. J., Strub, P. T., Tokmakian, R., 2002. Large-scale forcing of the Agulhas variability: the seasonal cycle. J. Phys. Oceanogr. $32,1228-1241$.

Meinen, C. S., Johns, W. E., Garzoli, S. L., van Sebille, E., Rayner, D., Kanzow, T., Baringer, M. O., 2013. Variability of the Deep Western Boundary Current at $26.5^{\circ} \mathrm{N}$ during 2004-2009. Deep-Sea Res. II 85, 154-168.

Morrow, R., Birol, F., 1998. Variability in the southeast Indian Ocean from altimetry: Forcing mechanisms for the Leeuwin Current. J. Geophys. Res. 103 (C9), $18529-18544$.

Nauw, J. J., van Aken, H. M., Webb, A., Lutjeharms, J. R. E., de Ruijter, W. P. M., 2008. Observations of the southern East Madagascar Current and undercurrent and countercurrent system. J. Geophys. Res. 113 (C08006), 1-15.

Ollitrault, M., Rannou, J. P., 2013. ANDRO: An Argo-based deep displacement dataset. J. Atms. and Ocean. Techn. 30, 759-788. 
Olson, D. B., Evans, R. H., 1986. Rings of the Agulhas Current. Deep-Sea Res. I 33, 27-42.

Park, Y. H., Gamberoni, L., Charriaud, E., 1993. Frontal structure, water masses, and circulation in the Crozet Basin. J. Geophys. Res. C7, 1236112385.

Ridderinkhof, H., van der Werf, P. M., Ullgren, J. E., van Aken, H. M., van Leeuwen, P. J., de Ruijter, W. P. M., 2010. Seasonal and interannual variability in the Mozambique Channel from moored current observations. J. Geophys. Res. 115 (C06010), 1-18.

Ridderinkhof, W., Le Bars, D., von der Heydt, A. S., de Ruijter, W. P. M., 2013. Dipoles of the South East Madagascar Current. Geophys. Res. Lett. $40,558-562$.

Rintoul, S. R., Sokolov, S., Church, J., 2002. A 6 year record of baroclinic transport variability of the Atartic Circumpolar Current at $140^{\circ} \mathrm{E}$ derived from expandable bathythermograph and altimeter measurements. J. Geophys. Res. 107 (C10), 19-1-19-22).

Rio, M. H., Guinehut, S., Larnicol, G., 2011. New CNES-CLS09 global mean dynamic topography computed from the combination of GRACE data, altimetry, and in situ measurements. J. Geophys. Res. 116, 1-25.

Schiller, A., Oke, P., Brassington, G., Entel, M., Fiedler, R., Griffin, D., Mansbridge, J., 2008. Eddy-resolving ocean circulation in the AsianAustralian region inferred from an ocean reanalysis effort. Prog. Oceanogr. 76, 334-365. 
Schott, F., Fieux, M., Swallow, J., Zantopp, R., 1988. The boundary currents east and north of Madagascar 2. Direct measurements and model comparisons. J. Geophys. Res. 93 (C5), 4963-4974.

Schouten, M., May 2001. Indian-Atlantic interocean exchange: variability and controls. Ph.D. thesis, Utrecht University.

Schouten, M. W., de Ruijter, W. P. M., van Leeuwen, P. J., Dijkstra, H. A., 2002. An oceanic teleconection between the equatorial and southern Indian Ocean. Geophys. Res. Lett. 29, 59-1-59-4.

Siedler, G., Rouault, M., Lutjeharms, J. R. E., 2006. Structure and origin of the subtropical South Indian Ocean Countercurrent. Geophys. Res. Lett. $33,1-5$.

Swallow, J., Fieux, M., Schott, F., 1988. The boundary currents east and north of Madagascar 1. Geostrophic currents and transports. J. Geophys. Res. 93 (C5), 4951-4962.

Swallow, J. C., Worthington, L. V., 1961. An observation of a deep countercurrent in the Western North Atlantic. Deep-Sea Res. 8, 1-19.

Torrence, C., Compo, G. P., 1998. A practical guide to wavelet analysis. Bull. Am. Meteorol. Soc. 79 (1), 61-78.

Ullgren, J. E., van Aken, H. M., Ridderinkhof, H., de Ruijter, W. P. M., 2012. The hydrography of the Mozambique Channel from six years of continuous temperature, salinity, and velocity observations. Deep-Sea Res. I 69, 36-50. 
800

801

802

803

804

805

806

807

808

van Aken, H. M., Ridderinkhof, H., de Ruijter, W. P. M., 2004. North Atlantic Deep Water in the south-western Indian Ocean. Deep-Sea Res. I 51, $755-776$.

Warren, B. A., III, T. W., LaCasce, J. H., 2002. Forced resonant undulation in the deep Mascarene Basin. Deep-Sea Res. II 49, 1513-1526.

Weijer, W., 2008. Normal modes of the Mascarene Basin. Deep-Sea Res. I 55 (1), 128-136.

Wyrtki, K., 1971. Oceanographic Atlas of the International Indian Ocean Expedition. National Science Foundation, Washington, D.C. 